\title{
Pengaruh Agresivitas Pajak terhadap Pengungkapan Corporate Social Responsibility (Studi terhadap Perusahaan Manufaktur yang Terdaftar di Bursa Efek Indonesia Tahun 2012 - 2016)
}

\author{
* Marghalina Bestharita Fajariati \\ Fakultas Ekonomi dan Bisnis, Universitas Bhayangkara, Indonesia
}

DOI: $10.46821 /$ equity.v1i2.176

\begin{abstract}
ABSTRAK
Penelitian ini bertujuan untuk menguji pengaruh agresivitas pajak terhadap pengungkapan corporate social responsibility (CSR). Variabel dependen yang digunakan dalam penelitian ini adalah pengungkapan corporate social responsibility (CSR), sedangkan variabel independen dalam penelitian ini adalah agresivitas pajak yang diukur dengan menggunakan effective tax rate (ETR). Penelitian ini menggunakan beberapa variabel control, yaitu ukuran perusahaan (SIZE), leverage (LEV), dan return on asset (ROA). Sampel penelitian ini adalah perusahaan manufaktur yang terdaftar di Bursa Efek Indonesia (BEI) periode tahun 2012-2016. Sampel dipilih menggunakan metode purposive sampling dan diperoleh 36 perusahaan per tahun yang memenuhi kriteria pengujian. Total sampel dalam penelitian ini adalah 180 perusahaan. Penelitian ini menggunakan pendekatan kuantitatif dengan alat uji analisis menggunakan model analisis regresi berganda ordinary least square dengan bantuan software SPSS versi 24. Hasil penelitian menunjukkan bahwa agresivitas pajak tidak berpengaruh terhadap pengungkapan corporate social responsibility (CSR).
\end{abstract}

Kata Kunci: Corporate Social Responsibility,Agresivitas Pajak, Teori Legitimasi.

\begin{abstract}
This study aims to examine the effect of tax aggressiveness on corporate social responsibility disclosure (CSR). The dependent variable used in this study is the disclosure of corporate social responsibility (CSR), while the independent variable in this study is the tax aggressiveness measured by using effective tax rate (ETR). This research uses several control variables, namely firm size (SIZE), leverage (LEV), and return on asset (ROA). The sample of this research is a manufacturing company listed on Indonesian Stock Exchange (BEI) period 20122016. Samples were chosen using purposive sampling method and obtained 36 companies per year that meet the criteria of testing. The total sample in this research is 180 companies. This research uses quantitative approach with analytical test using ordinary least square regression analysis model with the help of SPSS version 24 software. The results showed that tax aggressiveness did not affect the disclosure of corporate social responsibility (CSR).
\end{abstract}

Keywords: Corporate Social Responsibility, Corporate Tax Aggressiveness, Legitimacy Theory.

*Corresponding Author:

Email: marghalina26@gmail.com 


\section{PENDAHULUAN}

Perusahaan yang melakukan kegiatan usaha harus memenuhi kewajiban perpajakan sesuai dengan peraturan perundang-undangan perpajakan yang berlaku pada negara tempat perusahaan itu melakukan kegiatan usaha.Perusahaan menekan biaya dengan meminimalkan kewajiban membayar pajak karena biaya pajak akan menurunkan laba setelah pajak (after tax profit), tingkat pengembalian (rate of return), dan arus kas (cash flow) (Suandy, 2011:5). Tindakan manajerial yang dirancang untuk meminimalkan pajak perusahaan melalui kegiatan agresivitas pajak menjadi fitur yang semakin umum di lingkungan perusahaan di seluruh dunia (Lanis dan Richardson, 2013). Agresivitas pajak adalah suatu tindakan yang bertujuan untuk memperkecil jumlah kewajiban pembayaran pajak perusahaan.Menurut Lanis dan Richardson (2013), pandangan masyarakat mengenai perusahaan yang melakukan tindakan agresivitas pajak dianggap telah membentuk suatu kegiatan yang tidak bertanggung jawab secara sosial dan tidak sah.Oleh karena itu perusahaan yang melakukan agresivitas pajak tidak memperoleh legitimasi. Teori legitimasi tersebut juga mengungkapkan bahwa informasi pengungkapan dalam laporan tahunan berbentuk laporan pengungkapan CSR digunakan untuk mengurangi konsentrasi publik dan membantu perusahaan untuk memperoleh legitimasi.

Banyaknya perusahaan yang dianggap telah memberi kontribusi bagi kemajuan ekonomi dan teknologi tetapi perusahaan tersebut mendapat kritik karena telah menciptakan masalah sosial seperti polusi, penyusutan sumber daya, limbah, mutu dan keamanan produk. Adanya dampak pada lingkungan tersebut mempengaruhi kesadaran masyarakat akan pentingnya melaksanakan tanggung jawab sosial atau Corporate Social Responsibility (CSR) (Plorensia dan Hardiningsih, 2015).Menurut Kotler dan Nancy (2005:4), Corporate Social Responsibility (CSR) adalah suatu cara yang dilakukan perusahaan guna meningkatkan kesejahterannya dengan melakukan praktik bisnis yang tergolong baik dan mengkontribusikan sebagian dari sumber daya yang dimiliki oleh suatu perusahaan. Pengungkapan Corporate Social Responsibilit merupakan suatu kewajiban bagi setiap perusahaan yang diatur oleh pemerintah dalam Undangundang RI No. 40 tahun 2007 pasal 74 tentang "Tanggung Jawab Sosial dan Lingkungan". Undang-undang tersebut mengamanatkan bahwa "Perseroan yang menjalankan kegiatan usahanya di bidang dan/atau berkaitan dengan sumber daya alam wajib melaksanakan Tanggung Jawab Sosial dan Lingkungan".Pernyataan yang berbeda bahwa CSR masih merupakan bentuk sukarela yang dilakukan oleh perusahaan. Aktivitas CSR pada dasarnya dilakukan untuk memberikan kontribusi kepada para stakeholder perusahaan. Untuk menjaga keberlangsungan hidupnya, perusahaan harus menjaga hubungan baik dengan stakeholder. Perusahaan harus memperhatikan masalah-masalah sosial dan lingkungan sehingga perusahaan bisa memberikan nilai tambah pada stakeholdernya.

Salah satu faktor yang dapat mempengaruhi CSR adalah agresivitas pajak. Perusahaan yang melakukan agresivitas pajak berusaha untuk menekan biaya dengan meminimalkan kewajiban membayar pajak. Oleh karena itu, penelitian ini dilakukan untuk menjawab, "Apakah agresivitas pajak berpengaruh positif terhadap Pengungkapan Corporate Social Responsibilit (Studi terhadap Perusahaan Manufaktur yang terdaftar di Bursa Efek Indonesia Tahun 2012 2016) ?" 


\section{TINJAUAN PUSTAKA}

\section{Teori Legitimasi}

Legitimasi dapat dikatakan sebagai manfaat atau sumber potensial bagi perusahaan untuk dapat bertahan hidup, maka ketika ada perbedaan antara nilai nilai perusahaan dengan nilai - nilai sosial masyarakat yang sering dinamakan "legitimacy gap", hal tersebut dapat memengaruhi kemampuan perusahaan dalam melanjutkan kegiatan usahanya serta mengancam posisi perusahaan.Perusahaan yang cenderung melakukan agresivitas pajak akan mendapat citra buruk dari masyarakat dan perusahaan menganggap hal tersebut merupakan suatu kerugian. Maka perusahaan akan mengungkapkan informasi tanggung jawab sosialnya untuk memberikan legitimasi aktivitas perusahaan dimata masyarakat bahwa perusahaan telah berorientasi pada keberpihakan terhadap masyarakat luas.

\section{Teori Stakeholder}

Teori Stakeholder menyatakan bahwa perusahaan bukanlah entitas yang hanya beroperasi untuk kepentingannya sendiri namun harus memberikan manfaat bagi stakeholdernya (pemegang saham, kreditor, konsumen, supplier, pemerintah, masyarakat, analisis, dan pihak lain) (Chariri,2008). Dengan kata lain, perusahaan dalam beroperasi membutuhkan bantuan dari pihak luar salah satunya adalah dukungan dari masyarakat.Perusahaan dituntut untuk dapat memenuhi harapan masyarakat (kelompok stakeholder) melalui pelaksanaan suatu tanggung jawab sosial perusahaan dan apabila tidak dapat memenuhi harapan masyarakat tentunya akan menimbulkan penyebaran informasi negatif tentang perusahaan tersebut. Stakeholder menyadari adanya hal yang dapat menambah nilai suatu perusahaan.Salah satu caranya dengan melakukan kegiatan perusahaan yang berhubungan dengan aktivitas sosial atau disclosure corporate social responsibility (CSR).

\section{Definisi Pajak}

Definisi pajak menurut Undang - Undang Nomor 16 tahun 2009 tentang perubahan keempat atas Undang - Undang Nomor 6 Tahun 1983 tentang Ketentuan Umum dan Tata Cara Perpajakan pada pasal 1 ayat 1, yaitu: "Pajak adalah kontribusi wajib kepada negara yang terutang oleh orang pribadi atau badan yang bersifat memaksa berdasarkan Undang - Undang, dengan tidak mendapatkan imbalan secara langsung dan digunakan untuk keperluan negara bagi sebesar - besarnya kemakmuran rakyat".

\section{Manajemen Pajak}

Manajemen pajak merupakan upaya dalam melakukan penghematan pajak secara legal.Manajemen pajak adalah sarana untuk memenuhi kewajiban perpajakan dengan benar, tetapi jumlah pajak yang dibayar dapat ditekan serendah mungkin untuk memperoleh laba dan likuiditas yang diharapkan (Sophar Lumbantoruan, 1996 dalam Suandy, 2016).Suandy (2016) menyebutkan bahwa tujuan dari manajemen pajak terbagi menjadi dua, yaitu menerpakan peraturan perpajakan secara benar dan usaha efisiensi untuk mencapai laba dan likuiditas yang seharusnya. 


\section{Perencanaan Pajak}

Perencanaan pajak adalah langkah awal dalam manajemen pajak. Pada tahap ini dilakukan pengumpulan dan penelitian terhadap peraturan perpajakan agar dapat diseleksi jenis tindakan penghematan pajak yang akan dilakukan. Tujuan perencanaan pajak adalah merekayasa agar beban pajak (tax burden) dapat ditekan serendah mungkin dengan memanfaatkan peraturan yang ada untuk memaksimalkan penghasilan setelah pajak (after tax return).

\section{Agresivitas Pajak}

Frank et al (2006) dalam Lanis dan Richardson (2013:78) mendefinisikan agresivitas pajak sebagai tindakan merekayasa pendapatan kena pajak yang dilakukan perusahaan melalui tindakan perencanaan pajak. Pembayaran pajak perusahaan memang seharusnya memiliki implikasi penting bagi masyarakat dan sosial karena membentuk fungsi dalam membantu mendanai penyediaan barang publik dalam masyarakat, termasuk hal - hal seperti pendidikan, pertahanan nasional, kesehatan masyarakat, transportasi umum, dan penegakan hukum (Friese, et al, 2008; dalam Lanis dan Richardson, 2012). Slemrod (2004), dalam Balakrishnan, et al. (2011) berpendapat bahwa agresivitas pajak merupakan kegiatan yang lebih spesifik, yaitu mencakup transaksi yang tujuan utamanya adalah untuk menurunkan kewajiban pajak perusahaan dan menyatakan bahwa perusahaan yang agresif terhadap pajak ditandai dengan transparansi yang lebih rendah.

\section{Corporate Social Responsibility (CSR)}

Tanggung jawab sosial atau sering disebut Corporate Social Responsibility merupakan kemampuan suatu perusahaan dalam menutupi implikasi lingkungan yang berasal dari produk, operasi dan fasilitas perusahaan.CSR adalah sebuah pendekatan dimana perusahaan mengintegrasikan kepedulian sosial dalam operasi bisnis mereka dan dalam interaksi mereka dengan para pemangku kepentingan (stakeholders) berdasarkan prinsip kesukarelaan dan kemitraan (Nuryana, 2005:83).Dalam hal ini, CSR merupakan bentuk timbal balik terhadap masyarakat sekitar terhadap aktivitas operasi perusahaan agar mendapatkan respons baik dari masyarakat.

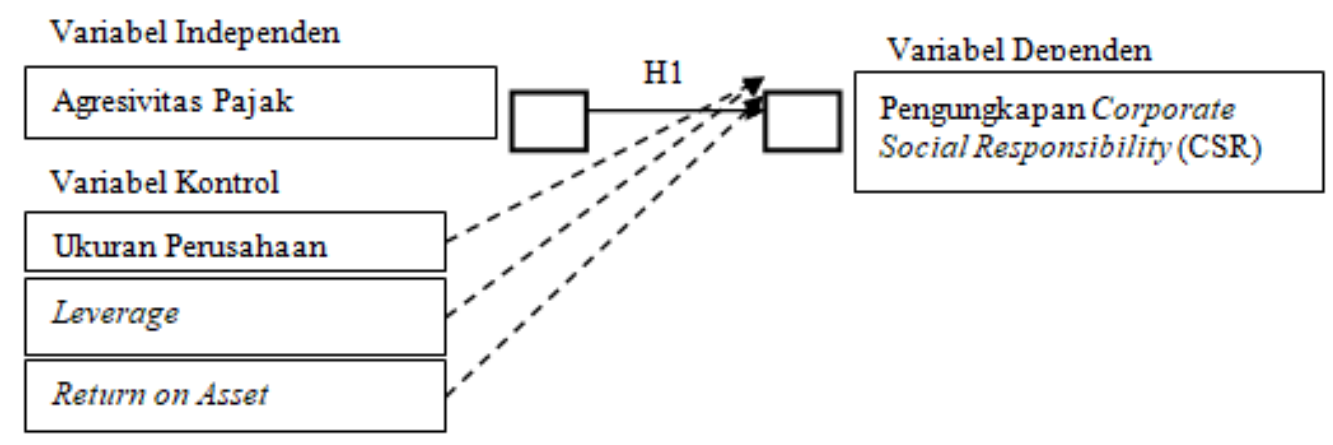

Gambar 1

Kerangka Pemikiran Teoritis 


\section{CSR Disclosure}

Pengungkapan tanggung jawab sosial perusahaan (CSR disclosure) yang sering juga disebut social disclosure, corporate social reporting, social accounting oleh Mathews (1995) dalam Sembiring (2005) atau corporate social responsibility oleh Hackston dan Milne (1996) dalam Sembiring (2005), merupakan proses pengkomunikasian dampak sosial dan lingkungan dari kegiatan ekonomi organisasi terhadap kelompok khusus yang berkepentingan dan terhadap masyarakat secara keseluruhan.

\section{METODE PENELITIAN}

\section{Definisi Operasional dan Pengukuran Variabel}

\section{Variabel Dependen}

Variabel dependen yang digunakan dalam penelitian ini adalah pengungkapan corporate social responsibility (CSR). Pengungkapan CSR diukur menggunakan indikator Global Reporting Initiative Generation dengan jumlah 84 pengungkapan. Maka rumus untuk pengukuran pengungkapan CSR yaitu:

$\mathrm{CSRIj}=\frac{\sum \boldsymbol{x} \boldsymbol{y} \boldsymbol{j}}{\boldsymbol{n} \boldsymbol{j}}$

CSRIj : Indeks luas pengungkapan tanggung jawab sosial dan lingkungan pada perusahaan $\mathrm{j}$

$\sum X y j:$ Nilai $1=$ jika item $\mathrm{j}$ diungkapkan; $0=$ jika item $\mathrm{j}$ tidak diungkapkan

$\mathrm{j}: \quad$ Item yang diharapkan diungkapkan

nj : $\quad$ Jumlah item untuk perusahaan $\mathrm{j} ; \mathrm{nj} \leq 84$

\section{Variabel Independen}

Variabel independen yang digunakan dalam penelitian ini adalah agresivitas pajak.Adapun yang menjadi proksi utama dalam penelitian ini adalah Effective Tax Rates (ETR).Proksi ETR dapat dihitung dari:

$\mathrm{ETR}=\frac{\text { Beban pajak penghasilan }}{\text { Pendapatan sebelum pajak }}$

\section{Variabel Kontrol}

\section{Ukuran Perusahaan (SIZE)}

Ukuran perusahaan diukur dengan cara :

Size $=$ Log natural total asset

\section{Leverage (LEV)}

Leverage diukur dengan cara :

$\mathrm{LEV}=\frac{\text { Total hutang }}{\text { Total aset }}$

\section{Return on Asset (ROA)}

ROA diukur dengan rumus:

ROA $=\frac{\text { Pendapatan sebelum pajak }(\text { EBIT })}{\text { Total aset }}$

\section{Populasi dan Sampel Penelitian}

\section{Populasi Penelitian}

Populasi yang digunakan dalam penelitian ini adalah semua perushaan manufaktur yang terdaftar di Bursa Efek Indonesia pada periode 2012-2016 . 


\section{Metode Pengambilan Sampel}

Adapun yang menjadi kriteria - kriteria dalam pengambilan sampel penelitian ini antara lain sebagai berikut: Perusahaan manufaktur yang listing di BEI tahun 2012-2016, menyajikan laporan keuangan yang telah diaudit secara lengkap selama 5 (lima) tahun berturut - turut, perusahaan menyajikan data yang lengkap terkait dengan variabel - variabel yang dipakai dalam penelitian, perusahaan yang menggunakan mata uang Rupiah, agar kriteria pengukuran nilai mata uangnya sama, perusahaan yang memiliki profitabilitas yang positif selama periode penelitian.

\section{Metode Pengumpulan Data}

Metode pengumpulan data yang digunakan dalam penelitian ini adalah metode studi pustaka dan metode dokumentasi. Data sekunder yang berasal dari laporan tahunan (annual report) dan laporan keuangan audited perusahaan yang terdaftar di Bursa Efek Indonesia (BEI) dalam situs resmi BEI yaitu www.idx.co.id.

\section{Pengujian Hipotesis}

Metode analisis data yang digunakan dalam penelitian ini adalah menggunakan model regresi linier Ordinary Least Square (OLS). Model persamaan regresi pada penelitian ini adalah sebagai berikut:

\section{$T C S R=\alpha 0+\beta 1 E T R+\beta 2 S I Z E+\beta 3 L E V+\beta 3 R O A+e$}

Keterangan:

TCSR : Total CSR yang diungkapkan oleh perusahaan dalam laporan keuangan perusahaan
$\alpha 0$
: Konstanta
$\beta 1, \beta 2, \beta 3 \quad$ : Koefisien masing - masing variabel
ETR : Agresivitas pajak perusahaan
SIZE : Ukuran perusahaan
LEV : Leverage
ROA : Return on asset
e $\quad$ error

\section{HASIL DAN PEMBAHASAN}

\section{Analisis Desktiptif}

Berdasarkan hasil penelitian dapat diketahui nilai minimum, maximum, nilai ratarata (mean), dan standar deviasi masing - masing variabel dari perusahaan dipaparkan pada Tabel 1.

\section{Tabel 1}

Deskripsi Variabel Penelitian Tahun 2012 sampai 2016

\begin{tabular}{lccccc}
\hline Variabel & $\mathrm{N}$ & Minimum & Maximum & Mean & Standard Deviation \\
\hline CSR & 180 & 0,0357 & 0,8333 & 0,3686 & 0,1547 \\
ETR & 180 & 0,0291 & 0,7099 & 0,2608 & 0,0825 \\
SIZE & 180 & 5,2607 & 13,1113 & 9,1746 & 2,3584 \\
LEV & 180 & 0,0735 & 0,8809 & 0,4008 & 0,1855 \\
ROA & 180 & 0,0063 & 0,8849 & 0,1547 & 0,1328
\end{tabular}

Sumber: Data Diolah, 2018 


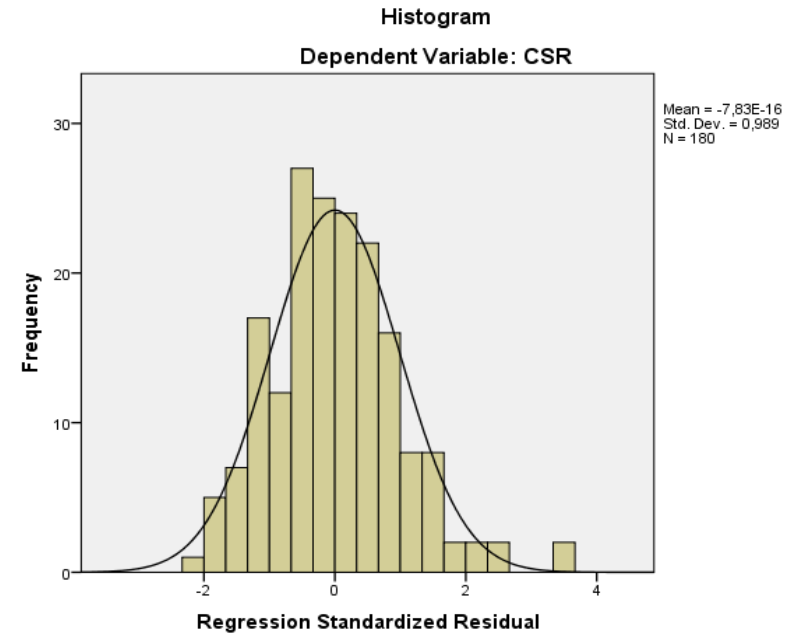

Sumber: Data Diolah, 2018

Gambar 2

Grafik Histogram

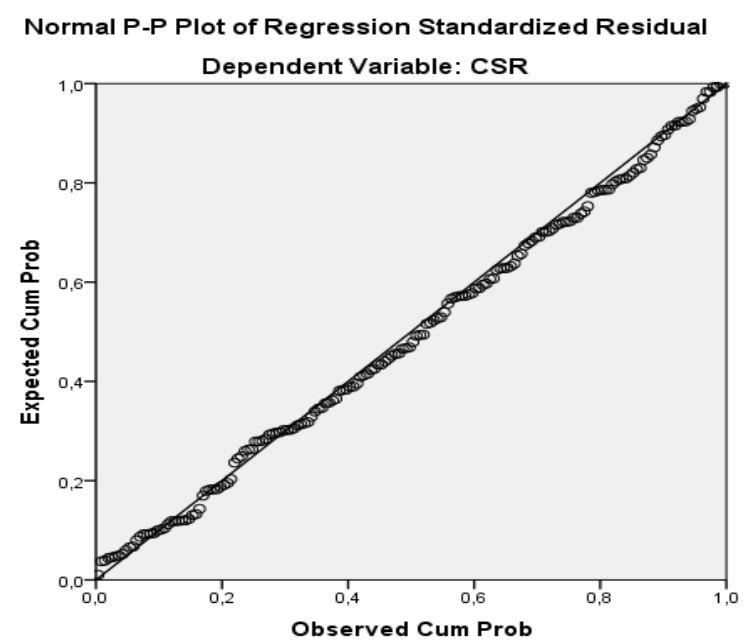

Sumber: Data Diolah, 2018

\section{Gambar 3}

\section{Grafik Normal Probability-Plot of Regresion Standardized Residual}

Dilihat dari hasil dimana standar deviasi masing-masing variabel lebih kecil dari nilai rata-rata (mean) menunjukkan bahwa variasi data kecil.

\section{Uji Normalitas}

Berdasarkan Gambar 2 dapat dilihat bahwa grafik histogram berada ditengah tengah sumbu $\mathrm{X}$ dan mengikuti distribusi normal, sehingga berdasarkan grafik histogram di atas data penelitian ini telah memenuhi uji normalitas.

Hasil uji normalitas oleh grafik Normal Probability-Plot of Regresion Standardized Residual berdasarkan Gambar 3dapat terlihat bahwa titik - titik berada di sekitar garis diagonal, sehingga data penelitian memiliki distribusi normal. 
Tabel 3

Hasil Uji Run Test

\begin{tabular}{lc}
\hline & Unstandardized Residual \\
\hline Test Value & $-0,00912$ \\
Cases $<$ Test Value & 90 \\
Cases $>=$ Test Value & 90 \\
Total Cases & 180 \\
Number of Runs & 57 \\
$Z$ & $-5,083$ \\
Asymp. Sig. (2-tailed) & 0,000 \\
\hline
\end{tabular}

a. Median

Sumber: Data Diolah, 2018

Tabel 4

Hasil Uji Run Test (2)

\begin{tabular}{lc}
\hline & Unstandardized Residual \\
\hline Test Value &,- 00677 \\
Cases $<$ Test Value & 89 \\
Cases $>=$ Test Value & 90 \\
Total Cases & 179 \\
Number of Runs & 91 \\
Z &, 075 \\
Asymp. Sig. (2-tailed) &, 940 \\
\hline
\end{tabular}

a. Median

Sumber: Data Diolah, 2018

\section{Uji Autokorelasi}

Berdasarkan tabel 5, hasil uji run test menunjukkan hasil Asymp. Sig. $<0,05$ yang menunjukkan terjadi gangguan autokorelasi. Karena model regresi terjadi gangguan autokorelasi, maka diperlukan tindakan transformasi data dengan memasukkan lag variabel. Hasil uji run test kedua setelah melalui proses transformasi data (Tabel 4).

Berdasarkan tabel 4, model regresi tersebut menunjukkan hasil Asymp. Sig. $>0,05$, sehingga dapat disimpulkan bahwa dalam model regresi ini tidak terjadi autokorelasi.

\section{Uji Heteroskedastisitas}

Uji gejala heteroskedastisitas dapat diketahui menggunakan metode chart (diagram scatterplot).

Berdasarkan Gambar 4 diagram scatterplot di atas menunjukkan bahwa titik-titik menyebar, tidak mengumpul, dan tidak membentuk pola yang khas. Hasil pengujian ini menyatakan bahwa model regresi terbebas dari gejala heteroskedastisitas.

\section{Analisis Model dan Pengujian Hipotesis}

Berikut adalah hasil rangkuman menggunakan model regresi linier berganda:

Mengacu pada hipotesis yang ada, maka rumus untuk persamaan regresinya dapat disimpulkan sebagai berikut:

TCSR = 0,667 - 0,247 ETR - 0,024 SIZE + 0,083 LEV - 0,310 ROA + 0,138 


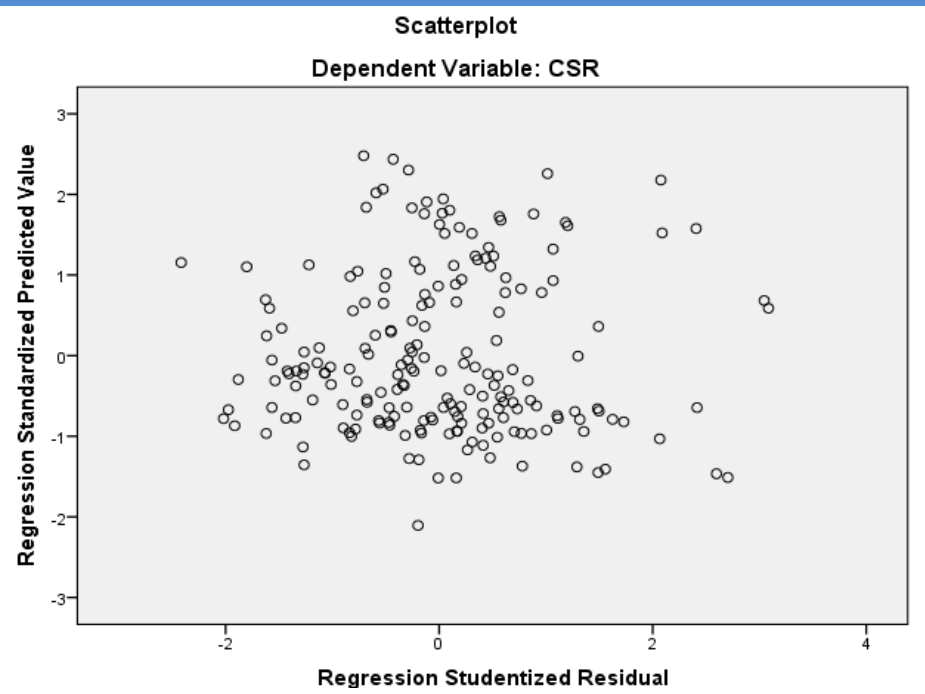

Sumber: Data Diolah, 2018

Gambar 5

Grafik Scatterplot Uji Heteroskedastisitas

Tabel 5

Hasil Analisis Regresi Berganda

\begin{tabular}{lcccc}
\hline \multirow{2}{*}{ Variabel } & \multicolumn{3}{c}{ MODEL REGRESI } \\
\cline { 2 - 5 } & Koefisien & Std. Error & $\mathrm{t}$ & Sig. \\
\hline Constant & 0,667 & 0,061 & 10,993 & 0,000 \\
ETR & $-0,247$ & 0,137 & $-1,804$ & 0,073 \\
SIZE & $-0,024$ & 0,005 & $-5,212$ & 0,000 \\
LEV & 0,083 & 0,062 & 1,346 & 0,180 \\
ROA & $-0,310$ & 0,084 & $-3,680$ & 0,000 \\
Koefisien Korelasi & 0,418 & & & \\
Koefisien Determinasi $\left(\mathrm{R}^{2}\right)$ & 0,175 & & & \\
Uji F & 9,280 & & & \\
Signifikansi F & 0,000 & & & \\
\hline
\end{tabular}

Sumber: Data Diolah, 2018

Konstanta $(\alpha 0)$ pada persamaan regresi linier berganda menunjukkan nilai sebesar 0,667 yang artinya apabila variabel agresivitas pajak, ukuran perusahaan, leverage, dan return on asset nilainya 0 (nol) atau konstan, maka variabel pengungkapan corporate social responsibility akan bernilai 0,667.

Variabel agresivitas pajak memiliki nilai koefisien regresi sebesar -0,247 yang berarti apabila agresivitas meningkat satu satuan, maka pengungkapan corporate social responsibility akan menurun sebesar 0,247. Sebaliknya jika pengungkapan corporate social responsibility meningkat satu satuan, maka agresivitas pajak akan menurun sebesar 0,247, dengan asumsi bahwa variabel lain konstan.

Variabel ukuran perusahaan memiliki nilai koefisien regresi sebesar $-0,024$ yang berarti apabila ukuran perusahaan meningkat satu satuan, maka pengungkapan corporate social responsibility akan menurun sebesar 0,024. Sebaliknya jika pengungkapan corporate social responsibility meningkat satu 
satuan, maka ukuran perusahaan akan menurun sebesar 0,024, dengan asumsi bahwa variabel lain konstan.

Variabel leverage memiliki nilai koefisien regresi sebesar 0,083 yang berarti apabila leverage meningkat satu satuan, maka pengungkapan corporate social responsibility akan menunjukkan peningkatan sebesar 0,083. Begitu pula jika leverage menurun satu satuan, maka pengungkapan corporate social responsibility juga akan menunjukkan penurunan sebesar 0,083 , dengan asumsi bahwa variabel lain konstan.

Variabel return on asset memiliki nilai koefisien regresi sebesar -0,310 yang berarti apabila return on asset meningkat satu satuan, maka pengungkapan corporate social responsibility akan menurun sebesar 0,310. Sebaliknya jika pengungkapan corporate social responsibility meningkat satu satuan, maka return on assetakan menurun sebesar 0,310, dengan asumsi bahwa variabel lain konstan.

Nilai e pada persamaan tersebut diperoleh sebesar 0,138. Bila nilai ini dibandingkan dengan standar deviasi variabel CSR yang dinyatakan sebesar 0,1547 , maka model regresi yang digunakan sudah baik karena nilai e dinyatakan lebih kecil dari nilai standar deviasi variabel CSR.

\section{Koefisien Determinasi Berganda dan Koefisien Korelasi Berganda}

Nilai koefisien determinasi $\left(\mathrm{R}^{2}\right)$ yang tertera pada Tabel 5 menunjukkan angka sebesar 0,175 , maksudnya adalah terdapat perubahan pada variabel terikat CSR yang disebabkan oleh variabel bebas ETR dan variabel kontrol SIZE, LEV, ROA yaitu sebesar 0,175 atau $17,5 \%$. Nilai koefisien korelasi yaitu sebesar 0,418, maksudnya adalah ETR (X) serta SIZE, LEV, ROA bersama-sama mempunyai hubungan atau korelasi yang sedang terhadap CSR (Y).

\section{Pengujian Hipotesis}

\section{Uji F}

Dari hasil pengujian yang dilakukan, diketahui bahwa nilai uji $\mathrm{F}$ sebesar 9,280 dengan tingkat signifikansi 0,000 . Nilai $F$ tabel menunjukkan angka 2,42 dan dengan demikian 9,280 > 2,42 yang memenuhi kriteria pengujian $\mathrm{F}$ hitung $>\mathrm{F}$ tabel. Nilai signifikansi ini juga lebih kecil dari 0,05 sehingga dapat disimpulkan bahwa variabel ETR (X), SIZE, LEV, ROA secara bersama - sama berpengaruh secara signifikan terhadap CSR (Y). Hal ini berarti menerima $\mathrm{H}_{1}$.

\section{Uji t}

Nilai uji t variabel agresivitas pajak (ETR) adalah sebesar -1,804 dengan tingkat signifikansi 0,073. Nilai t tabel menunjukkan angka 1,65361 dan dengan demikian $-1,804<1,65361$ yang memenuhi kriteria pengujian $\mathrm{t}$ hitung $<\mathrm{t}$ tabel. Nilai signifikansi ini juga lebih besar dari 0,05 sehingga dapat disimpulkan bahwa agresivitas pajak tidak berpengaruh signifikan terhadap pengungkapan corporate social responsibility.

Nilai uji t variabel ukuran perusahaan (SIZE) adalah sebesar -5,212 dengan tingkat signifikansi 0,000. Nilai $t$ tabel menunjukkan angka 1,65361 dan dengan demikian $-5,212<1,65361$ yang memenuhi kriteria pengujian $\mathrm{t}$ hitung $<\mathrm{t}$ tabel. Nilai signifikansi lebih kecil dari 0,05 sehingga dapat disimpulkan bahwa ukuran perusahaan berpengaruh signifikan terhadap pengungkapan corporate social responsibility. 
Nilai uji t variabel leverage (LEV) 1,346 dengan tingkat signifikansi 0,180 . Nilai $t$ tabel menunjukkan angka 1,65361 dan dengan demikian $-1,346<1,65361$ yang memenuhi kriteria pengujian $\mathrm{t}$ hitung $<\mathrm{t}$ tabel. Nilai signifikansi ini juga lebih besar dari 0,05 sehingga dapat disimpulkan bahwa leverage tidak berpengaruh signifikan terhadap pengungkapan corporate social responsibility.

Nilai uji t variabel return on asset (ROA) adalah sebesar -3,680 dengan tingkat signifikansi 0,000 . Nilai t tabel menunjukkan angka 1,65361 dan dengan demikian $-3,680<1,65361$ yang memenuhi kriteria pengujian $\mathrm{t}$ hitung $<\mathrm{t}$ tabel. Nilai signifikansi lebih kecil dari 0,05 sehingga dapat disimpulkan bahwa return on asset berpengaruh signifikan terhadap pengungkapan corporate social responsibility.

\section{Pembahasan}

Berdasarkan hasil pengujian secara parsial dapat diketahui bahwa hubungan antara agresivitas pajak dengan pengungkapan corporate social responsibility sangat rendah.Hal ini tidak sesuai dengan hipotesis penelitian yang menyebutkan bahwa agresivitas pajak memiliki pengaruh terhadap pengungkapan corporate social responsibility.

Penelitian ini juga sesuai dengan Nusantari, dkk (2015) bahwa agresivitas pajak tidak berpengaruh secara signifikan terhadap pengungkapan corporate social responsibility.Hal ini berarti perusahaan yang melakukan agresivitas pajak tidak perlu menutupi perilakunya dengan melakukan pengungkapan CSR.

Variabel ukuran perusahaan (SIZE) mempunyai hasil pengujian secara parsial yang berpengaruh signifikan terhadap pengungkapan corporate social responsibility. Hal ini mengindikasikan bahwa semakin besar ukuran perusahaan maka semakin besar kemungkinan perusahaan untuk melakukan pengungkapan CSR, karena perusahaan besar akan menjadi sorotan pemerintah, sehingga akan menimbulkan kecenderungan bagi para ppemangku kepentingan di perusahaan untuk berlaku patuh (Sari dan Anies, 2013).

Variabel leverage (LEV) mempunyai hasil pengujian secara parsial tidak berpengaruh signifikan terhadap pengungkapan corporate social responsibility. Tingkat hutang perusahaan merupakan aktivitas internal setiap perusahaan, dalam penelitian ini perusahaan tetap melakukan aktivitas pengungkapan CSR-nya, sehingga meskipun perusahaan tersebut memiliki nilai leverage yang tinggi tidak mempengaruhi mereka dalam melaksanakan program pengungkapan CSR, hal ini bertujuan agar menarik kepercayaan masyarakat untuk tetap menggunakan produk yang dihasilkan tersebut.

Variabel return on asset (ROA) mempunyai hasil pengujian secara parsial berpengaruh signifikan terhadap pengungkapan corporate social responsibility. Perusahaan yang memiliki laba yang tinggi akan menjadi sorotan sehingga perusahaan akan mengeluarkan biaya yang berkaitan dengan tanggung jawab sosial.

\section{SIMPULAN}

Berdasarkan hasil pengujian data yang dilakukan, dapat disimpulkan bahwa hasil regresi dalam penelitian ini tidak sesuai dengan hipotesis awal yang diajukan bahwa agresivitas pajak memiliki pengaruh terhadap pengungkapan corporate social responsibility dengan variabel kontrol ukuran perusahaa, leverage, dan return on asset pada perusahaan yang terdaftar di Bursa efek Indonesia tahun 
2012 - 2016. Hal ini berarti perusahaan yang melakukan agresivitas pajak tidak perlu menutupi perilakunya dengan melakukan pengungkapan CSR.Ukuran perusahaandan return on asset (ROA), memiliki hasil pengujian yang berpengaruh signifikan terhadap pengungkapan corporate social responsibility.Sedangkan leverage, memiliki hasil pengujian yang tidak berpengaruh signifikan terhadap pengungkapan corporate social responsibility.memiliki hasil pengujian berpengaruh signifikan terhadap pengungkapan corporate social responsibility.

\section{DAFTAR PUSTAKA}

Ahmad, N.N.N., dan M. Sulaiman. 2004. Environmental Disclosures in Malaysian Annual Reports: A Legitimacy Theory Perspective. International Journal of Commerce and Management, 14 (1), pp: 44-58

Arief, Subyantoro \& Suwarto. 2007. Metode dan Teknik Penelitian Sosial. Yogyakarta: C.V Andi Offset

Balakrishnan, K., J. Blouin, and W, Guay. 2011. "Does Tax Aggerssiveness Reduce Financial Reporting Transparancy?”.www.google.co.id.

Chariri, (2008). Kritik Sosial Atas Pemakaian Teori Dalam Penelitian Pengungkapan Sosial Dan Lingkungan, Semarang: Jurnal Maksi, Vol. 8 No.2, 2 Agustus 2008: 151-169.

Christensen, J. and Murphy, R. (2004). The social irresponsibility of corporate tax avoidance: taking CSR to the bottom line. Development, Vol. 47 No. 3, pp. $37-43$.

Darussalam. 2014. Kewajiban Pengungkapan Aggressive Tax Planning. Majalah Akuntan Indonesia. Edisi Juli-Agustus 2014. Hal 68-69.

Dewi, Ida Ayu Agung Wahyuning Candra dan Ni Gusti Putu Wirawati.2017. Pengaruh Agresivitas Pajak pada Corporate Social Responbility dengan Likuiditas sebagai Variabel Pemoderasi.E-Jurnal Akuntansi Universitas Udayana. Vol. 19.3: 1943-1969

Ghozali, Imam. 2011. Aplikasi Analisis Multivariate Dengan Program IBM SPSS 19 (edisi kelima). Semarang: Universitas Diponegoro.

Hadi, Nor. 2011. Corporate Social Responsibility. Yogyakarta: Graha Ilmu.

Hlaing, K.P. (2012). Organizational Architecture of Multinationals and Tax Agressiveness.University of Waterloo. Canada 
Kotler, P. and Nancy, L. 2005. Corporate Social Responsibility: Doing The Most Good For Your Company and Your Cause. Best Practices From Hewlett Packard, Ben \& Jerry's, and Other Leading Companies. Jhon Wiley \& Sons, Inc. United States of America.

Lako, Andreas. 2011. Dekonstruksi CSR \& Reformasi Paradigma Bisnis \& Akuntansi. Jakarta: Erlangga.

Lanis 2012. Corporate social responsibility and tax aggressiveness:An empirical analysis. Accounting, Auditing \& AccountabilityJournal, Vol. 31 No. 1. 2012. 86-108

Lanis, R. And G. Richardson. (2013). "Corporate Social Responsibility and Tax Aggresiveness: a test of legitimacy theory".Accounting Auditing and Accountability Journal, Vol.26 No.1,pp.75-100

Nuryana, Mu'man. 2005. Corporate Social Responsibility dan Kontribusi bagi Pembangunan Berkelanjutan, makalah yang disampaikan pada diklat pekerjaan sosial industri, Balai Besar Pendidikan dan Pelatihan Kesejahteraan Sosial (BBPPKS). Lembang, Bandung.

Nusantari, Nanda Inggar, dkk. 2015. Pengaruh Agresivitas Pajak Terhadap Corporate Social Responbility (CSR) (Studi pada Perusahaan yang Terdaftar dalam Indeks SRI KEHATI Tahun 2011-2013). Jurnal Administrasi Bisnis - Perpajakan (JAB). Vol. 5 No. 2. 2015: 1-9

Octaviana, Natasya Elma. 2014. Pengaruh Agresivitas Pajak Terhadap Corporate Social Responbility. Untuk menguji Teori Legitimasi. Jurnal Riset. Fakultas Ekonomika dan Bisnis Universitas Diponegoro, Semarang.

Plorensia, Winda dan Pancawati Hardiningsih.2015. Pengaruh Agresivitas Pajak dan Media Eksplosure terhadap Corporate Social Responbility. Dinamika Akuntansi, Keuangan dan Perbankan. Vol. 4, No. 2: 136-151

Pradnyadari, I Dewa Ayu Intan. 2015. Pengaruh Pengungkapan Corporate Social Responsibility terhadap Agresivitas Pajak (Studi Empiris pada Perusahaan Manufaktur yang Terdaftar di Bursa Efek Indonesia Tahun 2011 - 2013). Fakultas Ekonomika dan Bisnis Universitas Diponegoro, Semarang.

Sembiring, Eddy Rismanda. 2005. Karakteristik Perusahaan dan Pengungkapan Tanggung Jawab Sosial: Studi Empiris pada Perusahaan yang Tercatat di Bursa Efek Jakarta.Simposium Nasional Akuntansi VIII. 15-16 September 2005, Solo.

Suandy, Erly. 2011. Perencanaan Pajak. Jakarta : Salemba Empat. 
Sudana, I Made. 2009. Manajemen Keuangan Teori dan Praktik. Surabaya: Universitas Airlangga

Sugiyono. 2009. Metode Penelitian Kuantitatif, Kualitatif dan R\&D. Bandung: Alfabeta.

Sugiyono. 2011. Metode Penelitian Kuantitatif, Kualitatif dan R\&D. Bandung: Alfabeta.

Sumarsan, Thomas. 2012. Perpajakan Indonesia Edisi 3.Malang : Empat Dua Media.

Tiarawati, Winda Agustina. 2015. Analisis Pengaruh Pengungkapan Corporate Social ResponbilityTerhadap Tax Avoidance (Penghindaran Pajak) (Studi Empiris pada Perusahaan Manufaktur yang terdaftar di BEI Periode 20092013). Jurnal Akuntansi Indonesia. Vol. 4 No. 2: 123-142

Undang - Undang Nomor 16 Tahun 2009 tentang Ketentuan Umum dan Tata Cara Perpajakan

Undang-Undang Republik Indonesia Nomor 40 Tahun 2007 Tentang Perseroan Terbatas

Wahyudi, Dudi. 2015. Analisis Empiris Pengaruh Aktivitas Corporate Social Responbility (CSR) terhadap Penghindaran Pajak di Indonesia. Jurnal Lingkar Widyaiswara. Edisi 2 No. 4, Okt - Des 2015: p.05-17

Zain, Mohamad. 2008. Manajemen Perpajakan, Edisi 3 Cetakan 2. Jakarta: Salemba Empat. 